\title{
Child Immunizations: A Comparative Study Across States in India
}

\author{
Kingsuk Maity ${ }^{1}$, Pinaki Das ${ }^{2}$ and Shama Firdaush ${ }^{2}$ \\ ${ }^{1}$ Department of Economics, Shibpur Dinobundhoo Institution (College), West Bengal, India \\ ${ }^{2}$ Department of Economics with Rural Development, Vidyasagar University, West Bengal, India \\ "Corresponding author: ssdbic@gmail.com
}

\begin{abstract}
Childhood immunization programs have been suggested as an infrastructure to deliver vitamin, a supplement to children in developing countries. Health education and vaccinations prevent the spread of infectious disease. In long term, they can even lead to the end of those diseases in a given country. Thus, in this paper we have considered those vaccinations which are must for children against different types of serious disease suffered by them during their childhood days and have analyzed its coverage across states in India. The conclusion which we are able to draw is that the considered indicators have shown an improvement over the considered period i.e. from 2005-06 to 2015-16. Moreover, increment in the percentage of children who received most of the vaccinations by the public health facility over the decade has also increased in case of all the considered states.
\end{abstract}

Keywords: Childhood immunization, vitamin, diseases, vaccinations, public health facility

Childhood immunization programs have been suggested as an infrastructure to deliver vitamin, a supplement to children in developing countries. Immunization services provide an efficient and sustainable delivery channel for vitamin A supplements. Immunizing children against vaccine preventable diseases can greatly reduce childhood morbidity and mortality. To protect against the consequences of vitamin A deficiency, the World Health Organization recommends that high-dose vitamin A supplements should be given together with routine vaccines to children. Studies show that combining delivery of vitamin A supplementation with immunization is safe and does not have a negative effect on sero conversion of childhood vaccines. Vitamin A supplements are also given to treat sick children and xerophthalmia, and is recommended in the treatment of malnutrition. These time windows are dominated by three different childhood vaccines: BCG vaccine given at birth, diphtheria-tetanuspertussis (DTP) vaccine given between 1-5 months of age, and measles vaccine given at 9 months of age. These vaccines have been shown to have strong effects on mortality from infectious diseases in general, so-called non-specific effects. The live BCG and measles vaccine protect against more mortality than can be ascribed to the prevention of tuberculosis and measles, respectively. The inactivated DTP vaccine worryingly has been associated with increased mortality from other infectious diseases. Both positive and negative effects are strongest for girls. Thus, to optimize the child health intervention policy in low-income countries a shift in paradigm is needed. Health interventions should no longer be seen as merely specific and independent, and the policy should probably not be the same for boys and girls. Information on vaccination coverage was collected from the child's health card and direct reporting from the mother.

Bhatia M.R., Yesudian C.A.K., Gorter A. and K.R. Thankappan (2006) analyzed the concept of demand side financing and recommends piloting of a competitive voucher scheme as a mechanism for $\mathrm{RCH}$ services in India as because demand side 
subsidies not only overcome many drawbacks of the supply side financing but also provide the right incentives for efficiency. Borooah Vani K, Dilip Diwakar, and Nidhi Sadana Sabharwa (2014) presents econometric estimates regarding the relative strength of personal and household circumstances in determining the likelihood of utilizing the programmer's services and suggests a trade-off between quality and utilization by hypothesizing that the poor quality of services leads upper-caste mothers to exit the ICDS market and seek these services elsewhere. Ghoshal Rakhi and Anup Dhar (2012) explained that India's child sex ratio has gone awry despite several monitoring and corrective mechanisms and considered "undesirableness" of daughters as the root cause. Padhi Sakti (2001) explained that Infant and child mortality was not a simple function of the level of economic development, pace of economic growth or material prosperity. Further he continues that Proximate conditions have a direct bearing on infant and child mortality which cannot be influenced through increases in income and purchasing power alone and were outside the market domain. Shantha Sinha (2006) explained that in a democracy, every child must be regarded as indispensable and the government must be accountable for the deaths of children and mothers. Sinha Dipa (2015) explained that the Rapid Survey on Children conducted in 2013-14, released after an inexplicable delay and still in a summary fashion, show some but patchy progress between 2005-06 and 2013-14 in maternal and child health indicators. A preliminary analysis made by them indicates that in areas where special efforts, some results are seen. Thus, calling for greater investments in health and nutrition within a more comprehensive approach.

In this paper we have considered the basic vaccinations which are must for children against different types of serious disease suffered by a child during his childhood days and have analyzed its coverage across states in India. For this purpose, we have used the NFHS data. The basic vaccines which are must are given as follows:

- One dose of Bacillus Calmette-Guérin (BCG) vaccine, which protects against tuberculosis.

- Three doses of DPT vaccine, which protects against diphtheria, pertussis (whooping cough), and tetanus.
- Three doses of polio vaccine

- One dose of measles vaccine

\section{DEMOGRAPHIC PROFILE OF CHILDREN}

\section{Percentage of population below the 15 years of age}

Percentage of population below 15 years of age have been shown in Table 1. In India, there are 34.9 per cent people who were below 15 years of age in 2005-06 whereas this percentage has declined to 28.6 per cent in $2015-16$. Across the states, this percentage varied from 23.9 per cent to 43.8 per cent in 2005-06 and 20.2 per cent to 39.3 per cent in 2015-16. In 2005-06 and 2015-16, the top five states in terms of children under 15 year's age were Bihar, Meghalaya, Nagaland, Jharkhand and Arunachal Pradesh while the bottom five states were Goa, Kerala, Tamil Nadu, Delhi and Madhya Pradesh. The percentage of population below 15 years age have decreased in all the states over the decade but the highest decrease was in Nagaland, Rajasthan, Sikkim, Arunachal Pradesh and Madhya Pradesh whereas the least decrease was in Goa, Tamil Nadu and Meghalaya.

Table 1: Percentage share of Population below age 15 years across State in India

\begin{tabular}{ccccc}
\hline \multirow{2}{*}{ States } & \multicolumn{3}{c}{ NFHS-4 (2015-16) } & $\begin{array}{c}\text { NFHS-3 } \\
\text { (2005-06) }\end{array}$ \\
\cline { 2 - 5 } & Urban & Rural & Total & Total \\
\hline Andhra Pradesh & 23.2 & 23.9 & 23.7 & 30 \\
Arunachal Pradesh & 29.4 & 32.4 & 31.7 & 39.1 \\
Assam & 22.7 & 31.5 & 30.3 & 34.9 \\
Bihar & 34 & 40.1 & 39.3 & 43.8 \\
Chhattisgarh & 26.1 & 30.1 & 29.2 & 35.6 \\
Goa & 25 & 20 & 23.2 & 23.9 \\
Gujarat & 23.7 & 27.8 & 26 & 31.6 \\
Haryana & 27.4 & 28.1 & 27.8 & 34.7 \\
Himachal Pradesh & 20.8 & 25 & 24.6 & 29.3 \\
Jammu \& Kashmir & 23.4 & 29.1 & 27.4 & 32 \\
Jharkhand & 27.4 & 34.8 & 32.9 & 39.5 \\
Karnataka & 23.5 & 25 & 24.4 & 30.9 \\
Kerala & 20.3 & 20.1 & 20.2 & 25.4 \\
Madhya Pradesh & 26.9 & 31.6 & 30.3 & 37.3 \\
Maharashtra & 23.3 & 25.6 & 24.5 & 30.6 \\
Manipur & 27.5 & 31.4 & 29.9 & 33.3 \\
Meghalaya & 27.9 & 38.7 & 36.5 & 40.4 \\
Mizoram & 27.2 & 33.5 & 29.9 & 35 \\
& & & &
\end{tabular}




\begin{tabular}{ccccc} 
Nagaland & 30 & 33.1 & 32 & 39.9 \\
Odisha & 23.5 & 27.2 & 26.6 & 32.1 \\
Punjab & 23.1 & 23.3 & 23.2 & 29.6 \\
Rajasthan & 27.1 & 32.6 & 31.2 & 38.9 \\
Sikkim & 22.2 & 23.5 & 23.1 & 30.7 \\
Tamil Nadu & 22.4 & 24.1 & 23.3 & 26.6 \\
Tripura & 20.8 & 26 & 24.5 & 30 \\
Uttarakhand & 26.9 & 29.9 & 28.9 & 34.6 \\
Uttar Pradesh & 29.1 & 35.4 & 33.8 & 42.3 \\
West Bengal & 22.6 & 26.8 & 25.4 & 31.9 \\
India & 24.9 & 30.5 & 28.6 & 34.9 \\
Mean & 25.1 & 28.3 & 27.6 & 33.3 \\
SD & 3.1 & 5.1 & 4.4 & 4.9 \\
\hline
\end{tabular}

Sources: NFHS (2005-06) and (2015-16).

\section{Percentage of Children under age 5 years whose birth was registered across State in India, 2005-06 and 2015-16}

Information on birth registration of children under age five years is present in Table 2. At the time of the survey, 80 percentages of children under age five years had birth registered with the civil authority; this includes 62 per cent of children with birth certificates. Female and male children are equally likely to have their birth registered. Children in urban areas (89 per cent) are more likely then children in rural areas (76 per cent) to have their birth registered. Birth registration is lowest in Uttar Pradesh (60 per cent) and Bihar (61 per cent). Birth registration among children under age five years doubled over the considered decade (from 41 per cent to 80 per cent). The percentage of births that were registered increased by more than 50 percentage points over the decade in Jharkhand, Bihar, Uttar Pradesh, Madhya Pradesh, and Rajasthan.

Table 2: Percentage of Children under age 5 years whose birth was registered across State in India. 2005-06 and 2015-16

\begin{tabular}{ccccc}
\hline \multirow{2}{*}{ States } & \multicolumn{3}{c}{ NFHS-4 (2015-16) } & \multirow{2}{*}{$\begin{array}{c}\text { NFHS-3 } \\
\text { (2005-06) } \\
\text { Total }\end{array}$} \\
\cline { 2 - 4 } & Urban & Rural & Total & 41.3 \\
\hline $\begin{array}{c}\text { Andhra Pradesh } \\
\text { Arunachal }\end{array}$ & 90.1 & 79.9 & 82.7 & \\
Pradesh & 80.0 & 58.3 & 62.9 & 32.4 \\
Assam & 97.4 & 93.8 & 94.2 & 43 \\
Bihar & 64.5 & 60.3 & 60.7 & 5.8 \\
Chhattisgarh & 92.6 & 84.4 & 86.1 & 73
\end{tabular}

\begin{tabular}{ccccc} 
Goa & 98.9 & 99 & 98.9 & 94.7 \\
Gujarat & 97.2 & 94.8 & 95.8 & 85.6 \\
Haryana & 94.0 & 94.3 & 94.2 & 71.7 \\
Himachal Pradesh & 97.7 & 95.1 & 95.3 & 89 \\
Jammu \& Kashmir & 90.5 & 73.3 & 77.4 & 35.8 \\
Jharkhand & 77.7 & 61.9 & 65 & 9.1 \\
Karnataka & 95.0 & 94.9 & 94.9 & 58.3 \\
Kerala & 97.3 & 98.1 & 97.7 & 88.6 \\
Madhya Pradesh & 92.2 & 78.4 & 81.9 & 29.7 \\
Maharashtra & 95.8 & 94.6 & 95.1 & 80 \\
Manipur & 74.8 & 59.7 & 64.8 & 30.4 \\
Meghalaya & 89.2 & 78.4 & 79.8 & 43.3 \\
Mizoram & 97.8 & 98 & 97.9 & 93.3 \\
Nagaland & 80.2 & 63.8 & 68.3 & 36.9 \\
Odisha & 90.0 & 80.7 & 82.1 & 57 \\
Punjab & 97.3 & 99 & 98.3 & 76.8 \\
Rajasthan & 81.5 & 62.5 & 66.6 & 16.4 \\
Sikkim & 98.6 & 98.4 & 98.5 & 85.7 \\
Tamil Nadu & 98.5 & 98.2 & 98.3 & 85.8 \\
Tripura & 96.8 & 89.9 & 91.6 & 74.4 \\
Uttarakhand & 81.8 & 74.2 & 76.7 & 38.4 \\
Uttar Pradesh & 67.9 & 58.1 & 60.2 & 7.1 \\
West Bengal & 97.3 & 96.7 & 96.9 & 75.8 \\
India & 88.8 & 76.1 & 79.7 & 41.2 \\
Mean & 90.4 & 77.5 & 85.3 & 58.3 \\
SD & 8.70 & 35.1 & 12.7 & 27.4 \\
\hline
\end{tabular}

Sources: NFHS (2005-06) and (2015-16).

\section{Sex ratio at birth for children born in the last five years}

Sex ratio at birth for children represents the sex ratio at birth of female for every thousand males born within the last five years. Sex ratio at birth is less than 1000 in most of the states i.e. more male child has been born than female child. Kerala and Meghalaya are only in exception. That is the serious concern of the society. As many as 14 states have showed a decline in the sex ratio at birth. NorthEastern part of India is in crucial stage. Manipur, Mizoram and Sikkim have shown a tremendous fall in female sex ratio at birth per thousand males. In India, Sex ratio at birth for children born in the last five years (females per 1,000 males) has been shown in Table 3.

It was increased from 914 (in 2005-06) to 919 (in 2015-16) in India. Across the states, this ratio varies between 734 to 1091in 2005-06 and 809 to 1047 in 2015-16, the top five states in terms of under 
children born in the last five years sex ratio were Jharkhand, Arunachal Pradesh, Andhra Pradesh, Assam, Mizoram. And the bottom five position in 2015-16 namely Punjab, Haryana, Delhi, Rajasthan, Maharashtra in 2005-06. Among them four states retained in the bottom five position in 2015-16 namely Delhi, Haryana, Punjab, Rajasthan and Sikkim.

Table 3: Sex ratio at birth for children born in the last five years (females per 1,000 males) across State in India, 2005-06 and 2015-16

\begin{tabular}{|c|c|c|c|c|}
\hline \multirow{2}{*}{ State } & \multicolumn{3}{|c|}{ NFHS-4 (2015-16) } & \multirow{2}{*}{$\begin{array}{c}\text { NFHS-3 } \\
(2005-06) \\
\text { Total }\end{array}$} \\
\hline & Urban & Rural & Total & \\
\hline Andhra Pradesh & 1,010 & 880 & 914 & 1035 \\
\hline $\begin{array}{l}\text { Arunachal } \\
\text { Pradesh }\end{array}$ & 848 & 941 & 920 & 1,071 \\
\hline Assam & 794 & 945 & 929 & 1,033 \\
\hline Bihar & 942 & 933 & 934 & 893 \\
\hline Chhattisgarh & 922 & 992 & 977 & 972 \\
\hline Goa & 894 & 1,109 & 966 & 921 \\
\hline Gujarat & 835 & 960 & 907 & 906 \\
\hline Haryana & 785 & 867 & 836 & 762 \\
\hline Himachal Pradesh & 1,151 & 920 & 936 & 913 \\
\hline Jammu \& Kashmir & 902 & 928 & 922 & 902 \\
\hline Jharkhand & 893 & 926 & 919 & 1,091 \\
\hline Karnataka & 875 & 935 & 910 & 922 \\
\hline Kerala & 1,062 & 1,032 & 1,047 & 925 \\
\hline Madhya Pradesh & 899 & 937 & 927 & 960 \\
\hline Maharashtra & 920 & 927 & 924 & 867 \\
\hline Manipur & 962 & 962 & 962 & 1,014 \\
\hline Meghalaya & 891 & 1,030 & 1,009 & 907 \\
\hline Mizoram & 926 & 970 & 946 & 1,025 \\
\hline Nagaland & 1,014 & 935 & 956 & 984 \\
\hline Odisha & 966 & 927 & 933 & 963 \\
\hline Punjab & 792 & 909 & 860 & 734 \\
\hline Rajasthan & 845 & 899 & 887 & 847 \\
\hline Sikkim & 632 & 911 & 809 & 984 \\
\hline Tamil Nadu & 972 & 939 & 954 & 896 \\
\hline Tripura & 1,100 & 925 & 966 & 959 \\
\hline Uttarakhand & 817 & 924 & 888 & 912 \\
\hline Uttar Pradesh & 896 & 905 & 903 & 922 \\
\hline West Bengal & 902 & 984 & 960 & 976 \\
\hline India & 899 & 927 & 919 & 914 \\
\hline Mean & 905 & 943.3 & 923.8 & 932.6 \\
\hline $\mathrm{SD}$ & 104.2 & 182.3 & 52.3 & 82.2 \\
\hline
\end{tabular}

Sources: NFHS (2005-06) and (2015-16).

\section{COVERAGE OF VACCINATION ACROSS STATES IN INDIA}

The coverage BCG vaccine among children age 12-23 months is shown in Table 4 . The percentage of children age 12-23 months who have received BCG vaccination increased from 78.2 per cent in 2005-06 to 91.9 per cent in 2015-16. Across the state, this percentage varies between 77.2 per cent 98.9 per cent in urban areas, 65 per cent and 100 per cent in rural areas. The top five states are Goa, Jharkhand, Jammu \& Kashmir, Kerala, Sikkim, and bottom five states are Nagaland, Mizoram, Arunachal Pradesh, Himachal Pradesh, Uttar Pradesh in urban areas Among them three states were retained in the bottom five position in rural areas namely Nagaland, Arunachal Pradesh and Mizoram. The other two states were Tripura, Assam. The percentage of children who received BCG vaccine have increased in all states from 2005-06 to 2015-16 but it increased the most in Assam, Madhya Pradesh, Jharkhand, Bihar, Uttar Pradesh where as it increased the least in Goa, Mizoram, Gujarat, Kerala, Himachal Pradesh.

Table 4: Percentage Children (12-23 months) have received BCG vaccine across State in India, 2005-06 and 2015-16

\begin{tabular}{|c|c|c|c|c|}
\hline \multirow[t]{2}{*}{ States } & \multicolumn{3}{|c|}{ NFHS-4 (2015-16) } & \multirow{2}{*}{$\begin{array}{c}\text { NFHS-3 } \\
(2005-06) \\
\text { Total }\end{array}$} \\
\hline & Urban & Rural & Total & \\
\hline Andhra Pradesh & 97.7 & 97.1 & 97.3 & 93 \\
\hline Arunachal & & & & \\
\hline Pradesh & 80.4 & 68 & 70.9 & 57.7 \\
\hline Assam & 94.3 & 81 & 82.3 & 62.4 \\
\hline Bihar & 91.5 & 91.7 & 91.7 & 64.7 \\
\hline Chhattisgarh & 97.1 & 98.7 & 98.4 & 84.6 \\
\hline Goa & 100 & 100 & 100 & 96.8 \\
\hline Gujarat & 90.6 & 85.9 & 87.9 & 86.4 \\
\hline Haryana & 93.8 & 92.3 & 92.8 & 84.9 \\
\hline Himachal Pradesh & 88.1 & 95.3 & 94.8 & 97.2 \\
\hline Jammu \& Kashmir & 98.5 & 94.7 & 95.6 & 90.9 \\
\hline Jharkhand & 98.7 & 95.1 & 95.8 & 72.7 \\
\hline Karnataka & 89.2 & 95.2 & 92.5 & 87.8 \\
\hline Kerala & 98.3 & 97.9 & 98.1 & 96.3 \\
\hline Madhya Pradesh & 95 & 90.3 & 91.6 & 80.5 \\
\hline Maharashtra & 90.3 & 89.8 & 90 & 95.3 \\
\hline Manipur & 95.5 & 89.1 & 91.2 & 80 \\
\hline Meghalaya & 96.2 & 84.4 & 86 & 65.9 \\
\hline Mizoram & 79.2 & 71.4 & 75.3 & 86.4 \\
\hline
\end{tabular}




\begin{tabular}{ccccc} 
Nagaland & 77.2 & 65 & 68.4 & 46.3 \\
Odisha & 93.3 & 94.2 & 94.1 & 83.6 \\
Punjab & 97.7 & 98.5 & 98.2 & 88 \\
Rajasthan & 95.3 & 87 & 88.8 & 68.5 \\
Sikkim & 98.2 & 99.2 & 98.9 & 95.9 \\
Tamil Nadu & 96.2 & 93.9 & 94.9 & 99.5 \\
Tripura & 89.5 & 80 & 82.4 & 81.1 \\
Uttarakhand & 90.4 & 94 & 92.9 & 83.5 \\
Uttar Pradesh & 88.3 & 87.4 & 87.6 & 61 \\
West Bengal & 95.1 & 98.5 & 97.5 & 90.1 \\
India & 93.2 & 91.4 & 91.9 & 78.2 \\
Mean & 73.0 & 82.7 & 90.7 & 81.7 \\
SD & 58.5 & 39.4 & 8.1 & 13.7 \\
\hline
\end{tabular}

Sources: NFHS-3 (2005-06) and NFHS-4 (2015-16).

The coverage for each of the basic vaccination among children age 12-23 months is shown for the year 2005-06 and 2015-16 in Table 5. Coverage was least for the third dose of polio vaccine (73 per cent). Although, more children received the first doses of the DPT and polio vaccines than the second or third doses, the dropout rates were higher for polio. The percentage of children age 12-23 months who have received 3 doses of polio vaccination decreased from 78.2 per cent in 2005-06 to 72.8 per cent in 2015-16. Across the state, this percentage varies between 93.7 per cent and 92 per cent in urban areas, 59.1 per cent and 94.8 per cent in rural areas. The top five states are Manipur, Punjab, Jammu \& Kashmir, Chhattisgarh, Kerala and bottom states are Goa, Sikkim, Himachal Pradesh, Gujarat, Nagaland, in urban areas. Among them two states which retained in the bottom five position in rural areas were Goa, Nagaland. The percentage of children who received 3 doses of polio vaccine have increases for some states namely Madhya Pradesh, Kerala, West Bengal, Maharashtra, and Andhra Pradesh in 2015-16.

Table 5: Percentage of Children (12-23 months) who received 3 doses of polio vaccine across State in India, 2005-06 and 2015-16

\begin{tabular}{ccccc}
\hline \multirow{2}{*}{ States } & \multicolumn{3}{c}{ NFHS-4 (2015-16) } & $\begin{array}{c}\text { NFHS-3 } \\
(\mathbf{2 0 0 5 - 0 6 )}\end{array}$ \\
\cline { 2 - 5 } & Urban & Rural & Total & Total \\
\hline Andhra Pradesh & 64.9 & 75.2 & 72.3 & 79 \\
Arunachal Pradesh & 62.8 & 51.0 & 53.7 & 55.8 \\
Assam & 76.4 & 53.7 & 56.0 & 59 \\
Bihar & 71.6 & 73 & 72.9 & 82.4
\end{tabular}

\begin{tabular}{|c|c|c|c|c|}
\hline Chhattisgarh & 87.5 & 80.2 & 81.7 & 85.1 \\
\hline Goa & 93.7 & 91.4 & 92.9 & 87.2 \\
\hline Gujarat & 61.5 & 63 & 62.3 & 65.3 \\
\hline Haryana & 72.1 & 77 & 75.3 & 82.8 \\
\hline Himachal Pradesh & 67.3 & 83.6 & 82.4 & 88.6 \\
\hline Jammu \& Kashmir & 85.9 & 83.1 & 83.8 & 82.2 \\
\hline Jharkhand & 79.9 & 72.4 & 73.8 & 79.3 \\
\hline Karnataka & 70.0 & 78.2 & 74.6 & 73.8 \\
\hline Kerala & 89.6 & 87.6 & 88.5 & 83.1 \\
\hline Madhya Pradesh & 69.5 & 61.5 & 63.6 & 75.6 \\
\hline Maharashtra & 64.4 & 69.1 & 67 & 73.4 \\
\hline Manipur & 84.7 & 72.7 & 76.6 & 77.5 \\
\hline Meghalaya & 84.2 & 69 & 71.0 & 56.6 \\
\hline Mizoram & 64.2 & 59.1 & 61.7 & 63.5 \\
\hline Nagaland & 58.8 & 50.1 & 52.5 & 46.2 \\
\hline Odisha & 79.9 & 83.3 & 82.8 & 65.1 \\
\hline Punjab & 92.0 & 94.8 & 93.7 & 75.9 \\
\hline Rajasthan & 68.5 & 64.5 & 65.4 & 65.2 \\
\hline Sikkim & 87.1 & 88 & 87.7 & 85.6 \\
\hline Tamil Nadu & 84.4 & 80.7 & 82.3 & 87.8 \\
\hline Tripura & 78.9 & 67.2 & 70.1 & 65.3 \\
\hline Uttarakhand & 67.2 & 68.4 & 68 & 80.3 \\
\hline Uttar Pradesh & 69.8 & 67.8 & 68.3 & 87.6 \\
\hline West Bengal & 82.5 & 90.1 & 87.9 & 80.8 \\
\hline India & 73.4 & 72.6 & 72.8 & 78.2 \\
\hline Mean & 58.6 & 66.9 & 74.0 & 74.8 \\
\hline $\mathrm{SD}$ & 49.8 & 34.8 & 11.2 & 11.2 \\
\hline
\end{tabular}

Sources: NFHS-3 (2005-06) and NFHS-4 (2015-16).

The percentage of children age 12-23 months who have received 3 doses of DPT vaccine increases from 55.3 per cent in 2005-06 to 78.4 per cent in 2015-16. Across the state, this percentage varies from 58 per cent to 94 per cent in urban areas while 49.7 per cent to 95.7 per cent in rural areas. The top five states were Goa, Chhattisgarh, Punjab, Jammu \& Kashmir, Kerala and bottom states are Nagaland, Arunachal Pradesh, Mizoram, Uttar Pradesh, Haryana in urban areas Among them four states retained in the bottom five position in case of rural areas namely Nagaland, Arunachal Pradesh, Mizoram, Uttar Pradesh. The percentage of children who received 3 doses of DPT vaccine was highest in Manipur, Nagaland, Tripura, Tamil Nadu, Uttarakhand whereas the least was in Bihar, Himachal Pradesh, Goa, Haryana and Chhattisgarh (Table 6).

The percentage of children age 12-23 months who have received measles vaccine increases from 58.8 per cent in 2005-06 to 81.1 per cent in 2015-16. 
Across the state, this percentage varies from 58 per cent to 94 per cent in urban areas whereas from 49.7 per cent to 95.7 per cent in rural areas.

Table 6: Percentage of Children (12-23 months) received 3 doses of DPT vaccine across State in India, 2005-06 and 2015-16

\begin{tabular}{ccccc}
\hline \multirow{2}{*}{ States } & \multicolumn{2}{c}{ NFHS-4 (2015-16) } & $\begin{array}{c}\text { NFHS-3 } \\
\mathbf{( 2 0 0 5 - 0 6 )}\end{array}$ \\
\cline { 2 - 5 } & Urban & Rural & Total & Total \\
\hline Andhra Pradesh & 84.9 & 90.6 & 89 & 61 \\
Arunachal & 60 & 49.9 & 52.3 & 39.3 \\
Pradesh & & & & \\
Assam & 82.8 & 64.6 & 66.5 & 44.9 \\
Bihar & 79.3 & 80.2 & 80.2 & 46.1 \\
Chhattisgarh & 93.2 & 91 & 91.4 & 62.8 \\
Goa & 94 & 94.7 & 94.2 & 87.5 \\
Gujarat & 77.6 & 69.1 & 72.7 & 61.4 \\
Haryana & 71.6 & 79.2 & 76.5 & 74.2 \\
Himachal & 74.8 & 85.8 & 85 & 85.1 \\
Pradesh & & & & \\
Jammu \& & 92.4 & 86.7 & 88.1 & 84.5 \\
Kashmir & & & \\
Jharkhand & 87.1 & 81.3 & 82.4 & 40.3 \\
Karnataka & 72.7 & 82.1 & 77.9 & 74 \\
Kerala & 90.5 & 90.3 & 90.4 & 84 \\
Madhya Pradesh & 80.8 & 70.7 & 73.4 & 49.8 \\
Maharashtra & 75 & 74.8 & 74.9 & 76.1 \\
Manipur & 84.9 & 74.3 & 77.8 & 61.2 \\
Meghalaya & 88.1 & 71.8 & 74 & 47.3 \\
Mizoram & 63 & 60.4 & 61.7 & 66.8 \\
Nagaland & 58 & 49.7 & 52 & 28.7 \\
Odisha & 87.4 & 89.6 & 89.2 & 67.9 \\
Punjab & 92.6 & 95.7 & 94.5 & 70.5 \\
Rajasthan & 78.4 & 69.8 & 71.6 & 38.7 \\
Sikkim & 88.4 & 95 & 93 & 84.3 \\
Tamil Nadu & 86.3 & 83.1 & 84.5 & 95.7 \\
Tripura & 77.4 & 68.9 & 71.1 & 60.2 \\
Uttarakhand & 81 & 79.6 & 80 & 67.1 \\
Uttar Pradesh & 68.8 & 65.9 & 66.5 & 30 \\
West Bengal & 87.8 & 94.7 & 92.7 & 71.5 \\
India & 80.2 & 77.7 & 78.4 & 55.3 \\
\hline
\end{tabular}

Sources: NFHS-3 (2005-06) and NFHS-4 (2015-16).

The top five states were Goa, Chhattisgarh, Punjab, Jammu \& Kashmir, Kerala and the bottom states were Nagaland, Arunachal Pradesh, Mizoram, Uttar Pradesh and Haryana in urban areas. Among them, four states who retained in the bottom five position in rural areas were Nagaland, Arunachal
Pradesh, Mizoram and Uttar Pradesh. The states with highest percentage of children who received measles vaccine were Tripura, Sikkim, Rajasthan, Odisha, Tamil Nadu whereas the percentage was least in Chhattisgarh, Bihar, Goa, Assam, and Gujarat (Table 7).

Table 7: Percentage of Children (12-23 months) received Measles Vaccination across State in India, 2005-06 and 2015-16

\begin{tabular}{|c|c|c|c|c|}
\hline \multirow[t]{2}{*}{ States } & \multicolumn{3}{|c|}{ NFHS-4 (2015-16) } & \multirow{2}{*}{$\begin{array}{c}\text { NFHS-3 } \\
(2005-06)\end{array}$} \\
\hline & Urban & Rural & Total & \\
\hline Andhra Pradesh & 92 & 88.4 & 89.4 & 69 \\
\hline Arunachal Pradesh & 63.4 & 51.9 & 54.6 & 38.3 \\
\hline Assam & 86.1 & 69.7 & 71.4 & 37.4 \\
\hline Bihar & 77.3 & 79.6 & 79.4 & 40.4 \\
\hline Chhattisgarh & 96.3 & 93.3 & 93.9 & 62.5 \\
\hline Goa & 95.6 & -98.2 & 96.5 & 91.2 \\
\hline Gujarat & 76.7 & 73.7 & 75 & 65.7 \\
\hline Haryana & 78.8 & 79.1 & 79 & 75.5 \\
\hline Himachal Pradesh & 89.2 & 87.4 & 87.5 & 86.3 \\
\hline Jammu \& Kashmir & 92.1 & 84.2 & 86.2 & 78.3 \\
\hline Jharkhand & 85.4 & 82 & 82.6 & 47.6 \\
\hline Karnataka & 80.7 & 83.8 & 82.4 & 72 \\
\hline Kerala & 90.3 & 88.6 & 89.4 & 82.1 \\
\hline Madhya Pradesh & 85.1 & 77.7 & 79.6 & 61.4 \\
\hline Maharashtra & 82.6 & 82.9 & 82.8 & 84.7 \\
\hline Manipur & 81.8 & 70.4 & 74.2 & 52.9 \\
\hline Meghalaya & 86.6 & 69.7 & 71.9 & 43.8 \\
\hline Mizoram & 60.4 & 61.9 & 61.1 & 69.5 \\
\hline Nagaland & 57 & 47.8 & 50.4 & 27.3 \\
\hline Odisha & 84.7 & 88.5 & 87.9 & 66.5 \\
\hline Punjab & 92.7 & 93.3 & 93.1 & 78 \\
\hline Rajasthan & 86.5 & 75.8 & 78.1 & 42.7 \\
\hline Sikkim & 90 & 94.8 & 93.3 & 83.1 \\
\hline Tamil Nadu & 85.9 & 84.4 & 85.1 & 92.5 \\
\hline Tripura & 76.9 & 67.3 & 69.7 & 59.9 \\
\hline Uttarakhand & 77.7 & 81.8 & 80.6 & 71.6 \\
\hline Uttar Pradesh & 70.8 & 70.8 & 70.8 & 37.7 \\
\hline West Bengal & 88.4 & 94.5 & 92.8 & 74.7 \\
\hline India & 83.2 & 80.3 & 81.1 & 58.8 \\
\hline Mean & 63.9 & 72.3 & 80.3 & 64.5 \\
\hline SD & 54.6 & 37.3 & 11.6 & 18.4 \\
\hline
\end{tabular}

Sources: NFHS-3 (2005-06) and NFHS-4 (2015-16).

The percentage of children age 12-23 who were fully immunized increases from 43.5 per cent in 2005-06 to 62 per cent in 2015-16. Across the 
state, this percentage varies from 41.6 per cent to 88.7 per cent in urban areas and from 33.4 per cent to 90.1 per cent in rural areas. The top five states were Punjab, Goa, Chhattisgarh, Kerala and Jammu \& Kashmir whereas the bottom states were Nagaland, Arunachal Pradesh, Mizoram, Gujarat, Uttar Pradesh in urban areas Among them three states which retained in the bottom five position in rural areas were Nagaland, Arunachal Pradesh and Gujarat. The other two states were Madhya Pradesh, Assam. The states with the highest percentage of children who were fully immunized were Gujarat, Assam, Punjab, West Bengal and Mizoram whereas the least percentage was in Manipur Arunachal Pradesh, Chhattisgarh, Meghalaya, and Maharashtra (Table 8).

Table 8: Percentage of Children (12-23 months) fully immunized (BCG, measles, and 3 doses each of polio and DPT) Across State in India, 2005-06 and 2015-16

\begin{tabular}{|c|c|c|c|c|}
\hline \multirow{2}{*}{ State } & \multicolumn{3}{|c|}{ NFHS-4 (2015-16) } & \multirow{2}{*}{$\begin{array}{c}\begin{array}{c}\text { NFHS-3 } \\
(2005-06)\end{array} \\
\text { Total }\end{array}$} \\
\hline & Urban & Rural & Total & \\
\hline Andhra Pradesh & 60.4 & 67.2 & 65.3 & 46 \\
\hline Arunachal Pradesh & 44.2 & 36.4 & 38.2 & 28.4 \\
\hline Assam & 70.9 & 44.4 & 47.1 & 31.4 \\
\hline Bihar & 59.7 & 61.9 & 61.7 & 32.8 \\
\hline Chhattisgarh & 84.9 & 74.3 & 76.4 & 48.7 \\
\hline Goa & 87.7 & 90.1 & 88.4 & 78.6 \\
\hline Gujarat & 50.4 & 50.4 & 50.4 & 45.2 \\
\hline Haryana & 57 & 65.1 & 62.2 & 65.3 \\
\hline Himachal Pradesh & NA & NA & 69.5 & 74.2 \\
\hline Jammu \& Kashmir & 81.6 & 72.9 & 75.1 & 66.7 \\
\hline Jharkhand & 67 & 60.7 & 61.9 & 34.2 \\
\hline Karnataka & 59.8 & 64.8 & 62.6 & 55 \\
\hline Kerala & 82.2 & 82 & 82.1 & 75.3 \\
\hline Madhya Pradesh & 63 & 50.2 & 53.6 & 40.3 \\
\hline Maharashtra & 55.8 & 56.7 & 56.3 & 58.8 \\
\hline Manipur & 74.3 & 61.7 & 65.9 & 46.8 \\
\hline Meghalaya & 81.4 & 58.5 & 61.5 & 32.9 \\
\hline Mizoram & 49.8 & 51.3 & 50.5 & 46.5 \\
\hline Nagaland & 41.6 & 33.4 & 35.7 & 21 \\
\hline Odisha & 75 & 79.2 & 78.6 & 51.8 \\
\hline Punjab & 88.7 & 89.3 & 89.1 & 60.1 \\
\hline Rajasthan & 60.9 & 53.1 & 54.8 & 26.5 \\
\hline Sikkim & 81.4 & 83.7 & 83 & 69.6 \\
\hline Tamil Nadu & 73.3 & 66.8 & 69.7 & 80.9 \\
\hline Tripura & 64.2 & 51.2 & 54.5 & 49.7 \\
\hline Uttarakhand & 56.5 & 58.2 & 57.7 & 60 \\
\hline
\end{tabular}

\begin{tabular}{ccccc} 
Uttar Pradesh & 53.6 & 50.4 & 51.1 & 23 \\
West Bengal & 77.7 & 87.1 & 84.4 & 64.3 \\
India & 63.9 & 61.3 & 62 & 43.5 \\
Mean & 54.7 & 56.3 & 63.9 & 50.9 \\
SD & 41.2 & 33.8 & 14.1 & 17.4 \\
\hline
\end{tabular}

Sources: NFHS-3 (2005-06) and NFHS-4 (2015-16).

\section{COVERAGE OF VITAMIN-A SUPPLEMENTATION ACROSS STATES IN INDIA}

The percentage of children age 9-59 months who received Vitamin A dose in last 6 months increases from 16.5 per cent in 2005-06 to 60.2 per cent in 2015-16. Across the state, this percentage varied from 36.4 per cent to 88.3 per cent in urban areas whereas from 22.9 per cent and 91.7 per cent in rural areas. The top five states in this regard were Goa, Sikkim, Mizoram, Karnataka, Odisha and bottom states were Rajasthan, Manipur, Nagaland, Uttarakhand, and Uttar Pradesh in urban areas. Among them the three states who retained in the bottom five position in rural areas were Nagaland, Manipur, Uttarakhand, Rajasthan.

Table 9: Percentage of Children (9-59 months) who received Vitamin A dose in last 6 months across State in India, 2005-06 and 2015-16

\begin{tabular}{ccccc}
\hline \multirow{2}{*}{ States } & \multicolumn{3}{c}{ NFHS-4 (2015-16) } & (2005-06) \\
\cline { 2 - 5 } & Urban & Rural & Total & Total \\
\hline Andhra Pradesh & 73.5 & 71.6 & 72.1 & 21.1 \\
Arunachal Pradesh & 49 & 36.8 & 39.4 & 15.8 \\
Assam & 58.5 & 50.5 & 51.3 & 12.2 \\
Bihar & 58.6 & 62.7 & 62.3 & 25.1 \\
Chhattisgarh & 73.3 & 69.4 & 70.2 & 8.9 \\
Goa & 88.3 & 91.7 & 89.5 & 31 \\
Gujarat & 69.9 & 72.2 & 71.2 & 12.8 \\
Haryana & 65.7 & 67.3 & 66.7 & 10.5 \\
Himachal Pradesh & 51 & 65.4 & 64.3 & 26.7 \\
Jammu \& Kashmir & 68.1 & 63.6 & 64.7 & 12.6 \\
Jharkhand & 48.8 & 53.8 & 52.9 & 18 \\
Karnataka & 75.1 & 81.3 & 78.7 & 13.6 \\
Kerala & 74.3 & 74.5 & 74.4 & 31.5 \\
Madhya Pradesh & 65.6 & 58.6 & 60.4 & 12.5 \\
Maharashtra & 72.2 & 69.2 & 70.5 & 23.3 \\
Manipur & 39.1 & 28.4 & 32.1 & 11.2 \\
Meghalaya & 63.7 & 52.9 & 54.4 & 14.9 \\
Mizoram & 75.2 & 61.1 & 68.6 & 40.2 \\
Nagaland & 37.9 & 22.9 & 27.1 & 6.6 \\
& & & &
\end{tabular}




\begin{tabular}{ccccc} 
Odisha & 74.8 & 68.1 & 69.1 & 20.4 \\
Punjab & 69.3 & 71.5 & 70.6 & 14.6 \\
Rajasthan & 47.3 & 37.5 & 39.6 & 8.6 \\
Sikkim & 80.5 & 86.2 & 84.3 & 18 \\
Tamil Nadu & 65.9 & 70.5 & 68.3 & 33.1 \\
Tripura & 69.1 & 60.7 & 62.8 & 28.3 \\
Uttarakhand & 36.9 & 36.9 & 36.9 & 12.8 \\
Uttar Pradesh & 36.4 & 40.4 & 39.5 & 5.6 \\
West Bengal & 65.7 & 69.6 & 68.4 & 31.7 \\
India & 62.9 & 59.1 & 60.2 & 16.5 \\
Mean & 62.3 & 55.9 & 60.8 & 18.4 \\
SD & 14 & 30.2 & 15.6 & 9.1 \\
\hline
\end{tabular}

Sources: NFHS-3 (2005-06) and NFHS-4 (2015-16).

The state where there was the highest increase in the percentage of children who received Vitamin-A were Manipur, Odisha, Jharkhand, Uttarakhand, and Punjab. Whereas the least increment was in Chhattisgarh, Bihar, Assam, Arunachal Pradesh and Andhra Pradesh (Table 9).

\section{CHILD VACCINATIONS THROUGH PUBLIC HEALTH SECTOR ACROSS STATES IN INDIA}

The percentage of children age 12-23 months who received most of the vaccinations in public health facility increased from 82 per cent in 2005-06 to 90.7 per cent in 2015-16. Across the state, this percentage varied from 72.6 per cent to 94.7 per cent in urban areas, and from 81.7 per cent to 99.2 per cent in rural areas over the decade.

Table 10: Percentage of Children (12-23 months) received most of the vaccinations through public health facility across State in India, 2005-06 and 201516

\begin{tabular}{ccccc}
\hline \multirow{2}{*}{ States } & \multicolumn{3}{c}{ NFHS-4 (2015-16) } & (2005-06) \\
\cline { 2 - 5 } & Urban & Rural & Total & Total \\
\hline Andhra Pradesh & 83.4 & 94.9 & 91.6 & 43.4 \\
Arunachal & 90.3 & 95.1 & 93.9 & 95.4 \\
Pradesh & & & & \\
Assam & 77.3 & 95.3 & 93.3 & 87 \\
Bihar & 87 & 96.4 & 95.5 & 73.2 \\
Chhattisgarh & 87.6 & 98.6 & 96.4 & 93.8 \\
Goa & 72.7 & 86.4 & 77.2 & 83.2 \\
Gujarat & 78.2 & 93.9 & 87.1 & 82.2 \\
Haryana & 91.4 & 96.6 & 94.8 & 92.6 \\
Himachal Pradesh & 94.7 & 98.1 & 97.9 & 96.3
\end{tabular}

\begin{tabular}{ccccc} 
Jammu \& & 93.9 & 98.8 & 97.5 & 91.5 \\
Kashmir & & & & \\
Jharkhand & 81.5 & 98.3 & 95.3 & 83 \\
Karnataka & 77.8 & 96.1 & 88.2 & 74.8 \\
Kerala & 72.6 & 81.7 & 77.6 & 66 \\
Madhya Pradesh & 88.9 & 98.3 & 95.7 & 86.7 \\
Maharashtra & 78.5 & 92.3 & 86.2 & 79.6 \\
Manipur & 92.8 & 92.9 & 92.9 & 92.7 \\
Meghalaya & 81.1 & 94.3 & 92.4 & 87 \\
Mizoram & 86.8 & 98.3 & 92.2 & 93.7 \\
Nagaland & 84.6 & 94.7 & 91.7 & 93.1 \\
Odisha & 93.2 & 99.2 & 98.3 & 86.4 \\
Punjab & 80.4 & 94.3 & 89 & 85.5 \\
Rajasthan & 88.8 & 96 & 94.4 & 87.2 \\
Sikkim & 91.9 & 95.1 & 94.1 & 98.6 \\
Tamil Nadu & 78.7 & 91.9 & 86.1 & 75 \\
Tripura & 92.6 & 99.2 & 97.4 & 87.2 \\
Uttarakhand & 87.6 & 92.4 & 91 & 81.7 \\
Uttar Pradesh & 77.5 & 86.4 & 84.5 & 80.5 \\
West Bengal & 90.4 & 99 & 96.6 & 92.5 \\
India & 82.1 & 94.2 & 90.7 & 82 \\
Mean & 67.4 & 88.6 & 91.8 & 84.4 \\
SD & 53.6 & 37.7 & 5.5 & 11.1 \\
\hline & & & & \\
\hline
\end{tabular}

Sources: NFHS-3 (2005-06) and NFHS-4 (2015-16).

The top five states were Himachal Pradesh, Jammu \& Kashmir, Tripura, Manipur and Odisha while the bottom states were Kerala, Goa, Assam, Uttar Pradesh and Karnataka in urban areas. Among them the three states which retained in the bottom five position in rural areas were Kerala, Goa, Uttar Pradesh, Maharashtra, and Tamil Nadu. The states showing highest increase in the percentage of children who received most of the vaccinations in public health facility were Andhra Pradesh, Arunachal Pradesh, Bihar, Assam, and Chhattisgarh whereas the least occurred in West Bengal, Uttar Pradesh Odisha, Tamil Nadu and Uttarakhand (Table 10).

\section{CONCLUSION}

Percentage of population below 15 years of age has experienced reduction over the decade. In case of all the indicators considered to analyze child immunization it was observed that all the them namely birth registration among children under the age of five years, sex ratio at birth for the children born, percentage of children who received BCG vaccine, percentage of children who received 3 
doses of polio vaccine, coverage of DPT vaccine and measles vaccine, percentage of children who received Vitamin-A and the percentage of children who received most of the vaccinations by the public health facility has shown an improvement over the considered period i.e. from 2005-06 to 2015-16. Jharkhand, Bihar, Uttar Pradesh, Madhya Pradesh, and Rajasthan showed highest increment in case of birth registration. Assam, Madhya Pradesh, Jharkhand, Bihar, Uttar Pradesh showed the highest increment in the percentage of children who received BCG vaccine. Madhya Pradesh, Kerala, West Bengal, Maharashtra, and Andhra Pradesh showed the highest increase in the percentage of children who received 3 doses of polio vaccine. Coverage of DPT vaccine was highest in Manipur, Nagaland, Tripura, Tamil Nadu and Uttarakhand and the states showing highest increment in coverage for measles vaccine for children were Tripura, Sikkim, Rajasthan, Odisha and Tamil Nadu whereas the increment in the percentage of children who received most of the vaccinations by the public health facility over the decade has also increased in case of all the states.

\section{REFERENCES}

Bhatia, M.R., Yesudian, C.A.K., Gorter, A. and Thankappan, K.R. 2006, “Demand Side Financing for Reproductive and Child Health Services in India", Economic and Political Weekly, January 2006.

Borooah, V.K., Dilip Diwakar, and Nidhi Sadana Sabharwa 2014. Economic \& Political Weekly, 49(12).

Ghoshal, R. and Anup Dhar, 2012. "Child Sex Ratio and the Politics of 'Enemisation", Economic E Political Weekly, 47(49).

Government in India, ministry of health and family welfare, (1997 and 1991), Reproductive and child health programme.

India Health Care: Inspiring Possibilities. Challenging journey, McKinney and company, 2012.

NCPCR, Policy document on protection of children's Right in Areas of Civil Unrest.

Padhi, S. 2001. "Infant and Child Survival in Orissa: An Analysis with NFHS Data", Economic and Political Weekly, August 2001.

Sinha, D. 2015. "Maternal and Child Health Inching Ahead, Miles to Go", Economice Political Weekly, 50(49).

Sinha, S. 2006. "Infant Survival: A Political Challenge", Economic and Political Weekly, August 2006.

UNICEF, an overview of the Status of Drinking water and sanitation in India (2012-13), and State of the World's children Report, 2010: UNICEF. 
